\title{
ENTRE OLHARES, TAMBORES E AFETOS: ISHINDAIKO
}

\author{
Raissa Romano Cunha (Ciências Sociais - UEL) \\ Carla Delgado de Souza (Orientadora)
}

\section{RESUMO}

O grupo de Taiko (tambores japoneses) Ishindaiko, formado em Londrina em novembro de 2003, é considerado, devido aos títulos acumulados, o melhor grupo de Taiko do país. O presente estudo visa desenvolver, através de uma perspectiva antropológica, uma análise do grupo étnico-percussivo Ishindaiko, a partir do trabalho de campo realizado durante o ultimo ano, com duas incursões diretas. A relação entre a vivência dos jovens dentro do grupo e a importância para a construção da identidade, tanto coletiva quanto individual, constitui um dos eixos do trabalho. A abordagem principal será a partir de um diálogo com Michel Maffesoli, em sua obra "O tempo das tribos", com o intuito de observar como tal manifestação cultural tradicional, que vem sendo construídas pelos jovens nikkeis, é parte de um movimento de "reencantação do mundo" através do enaltecimento do "saber dos interstícios", com a ênfase na ação comunitária. Além desse aspecto, a sacralização do cotidiano através da prática do taiko, construindo ritos e tradições particulares, configura o outro eixo do trabalho, em diálogo com Victor Turner e Pierre Clastres.

Palavras-chaves: Taiko. Ritual. Tribalismo.

\section{INTRODUÇÃO}

A imigração japonesa para o Brasil teve inicio em 1908, data que marca a chegada do primeiro navio a um porto brasileiro. Após mais de 100 anos da chegada dos primeiros imigrantes, a memória das raízes orientais se mantêm viva e intimamente ligada às tradições do país de origem entre os seus descendentes. Os navios partiram do Japão carregados de memórias que continuam a ser tecidas, constantemente, em um culto à ancestralidade. Diversos nikkeis ${ }^{1}$ buscam manter elementos das tradições japonesas em seu cotidiano e em suas manifestações culturais, sendo um componente da construção da identidade práticas como o Taiko. O nome Taiko significa "tambores japoneses" e é usado para designar os instrumentos de percussão do Japão.

No Brasil, o Taiko se popularizou a partir da vinda de Yukihisa Oda, mestre japonês que visitou o país em 2002. O Sensei Oda colaborou na difusão do taiko viajando por todo o Brasil ensinando o taiko moderno, ou kumi-daiko ${ }^{2}$, além de ter ensinado a fabricar o Okedo, um dos principais instrumentos do taiko. Outro aspecto importante da influência de Yukihisa Oda foi a criação da ABT (Associação Brasileira de Taiko) em 2004, que conta hoje com diversos grupos de taiko filiados à instituição, concentrados principalmente em São Paulo e Paraná. Em primeiro de maio de 2003, Yukihisa Oda veio a Londrina e ofertou o curso que ministrava por todo o país.

\footnotetext{
${ }^{1}$ Descendentes de japoneses nascidos fora do Japão.

${ }^{2}$ Vários percussionistas e vários taikos. Conhecido como taiko de grupo.
} 


\section{SEMINÁRIO DE PESQUISA EM CIÊNCIAS HUMANAS - SEPECH \\ Humanidades, Estado e desafios didático-científicos \\ Londrina, 27 a 29 de julho de 2016}

O Ishindaiko surgiu em novembro de 2003, fundado por três jovens que participaram desse curso acerca da arte do Taiko. Lucas Muraguchi, um dos fundadores, permanece no grupo e é uma grande referência, não apenas para os tocadores do Ishindaiko, mas em todo Brasil.

A ABT realiza anualmente um campeonato de taiko que reúne os grupos de todo o país. O campeonato brasileiro de taiko está dividido em quatro categorias, sendo elas: Mirim, Junior, Livre, Odaiko e Master. A restrição de idade ocorre em três delas: Mirim são tocadores abaixo de 12 anos, Junior até 18 anos e Master acima de 45. As principais categorias do campeonato são o Junior (que possui como prêmio principal uma viagem ao Japão) e o Livre. O grupo Ishindaiko possui o maior numero de títulos, sendo hexacampeão brasileiro de taiko. A conquista dos títulos dentro deste campeonato é valorizado por todos os membros do grupo e a responsabilidade para manter a excelência e expectativas pesa em cada integrante.

O grupo Ishindaiko se destaca por inovações na forma de tocar devido, principalmente, as coreografias que fogem da maneira mais tradicional. Apesar de causar certo incomodo, em alguns casos, nos mais tradicionais, as inovações e a qualidade técnica que acompanham as coreografias comovem e encantam o público em geral. Segundo Muraguchi, o Ishindaiko é um grupo de inovação, composto pela mistura de diversos elementos, que combinam traços tanto do Kawasu Daiko do mestre Oda, quanto do Amanotaku, do mestre Watanabe. O segundo estilo é marcado fortemente por treinos pesados, e possui forte influencia na prática do grupo.

Apesar de pontuar alguns desses aspectos, minha proposta com esse artigo é outra. O Ishindaiko não é apenas um grupo de taiko. Em sua dinâmica interna e no discurso proferido por seus membros a respeito do grupo, é como se fossem um único corpo, apesar das particularidades individuais. Buscarei apresentar a partir de agora aspectos da organização interna do grupo e suas práticas, com o intuito de relacionar no final do artigo as experiências do campo com a produção teórica desenvolvida por Maffesoli em "O tempo das tribos". Essa pesquisa está em andamento enquanto trabalho de conclusão de curso, e o recorte voltado para o tribalismo e os aspectos rituais do cotidiano não se esgotam nessas paginas. A proposta é a apresentação de alguns elementos coletados no campo e as percepções e discussões que suscitaram.

\section{LAÇOS FAMILIARES E ORGANIZAÇÃO INTERNA}

O Ishindaiko é "formado pelos ideogramas I - um, SHIN - coração, e DAIKO taiko, que significa "tambores de uma só alma". O grupo pensa a si mesmo como uma família, valorizando os relacionamentos que são estabelecidos através do taiko. Os pais e mães dos tocadores são essenciais para a construção do grupo e são integrados a ele, compondo-o, tanto quanto seus filhos. Um dos exemplos que demonstra a presença ativa é a questão da alimentação.

As famílias dos tocadores estão divididas em cinco grupos que se revezam para trazer comidas durante os treinos que ocorrem aos sábados. Acompanhei também uma rotação interna em relação a comida dentro do Junior ${ }^{3}$, que reverenciava

\footnotetext{
${ }^{3}$ O Ishindaiko possuía para o campeonato de 2015 três divisões internas: dois grupos inscritos no Livre, formados por integrantes experientes, e um grupo para o Junior. Esse grupo do Junior estava composto
} 


\section{SEMINÁRIO DE PESQUISA EM CIÊNCIAS HUMANAS - SEPECH \\ Humanidades, Estado e desafios didático-científicos \\ Londrina, 27 a 29 de julho de 2016}

com Itadakimasu "obrigado pela comida" no inicio e termino das refeições, em respeito com a tradição nipônica. São também as mães e pais que atuam ativamente na organização de eventos promovidos pelo Ishindaiko, como no caso das apresentações no Teatro Marista, em que a família dos tocadores trabalhou na venda de ingresso, recepção, entre outras tarefas. É nítido o orgulho que as mães e pais sentem de seus filhos e do Ishindaiko no todo, e mais ainda, o orgulho de ser parte dessa história, de ser-Ishindaiko. Por outro lado, os tocadores apresentam grande respeito aos mais velhos, que são constantemente lembrados nas falas como fonte de inspiração para realizar as apresentações.

No caso da liderança, em um primeiro momento ao observar o grupo, podemos ser levados a crer que todas as tarefas, responsabilidades e os poderes da chefia estão centralizados em uma única figura: o líder, que atualmente é o Erick Takihara. De caráter rotativo, o líder ocupa diversas funções dentro do Ishindaiko, principalmente enquanto porta-voz dos tocadores frente aos pais e a comunidade externa. Apesar disso, é possível observar como há outras lideranças fortes no cotidiano e andamento do grupo, que cumprem funções especificas.

Há as lideranças dos treinos, como por exemplo, a Cintia no Junior, que é responsável por eles não apenas enquanto treinadora, mas também fora dos treinos, ao organizar encontros para que a interação seja maior e os laços cada vez mais fortes. É de extrema importância para o Ishindaiko que ocorra essa união entre seus membros, que os laços familiares sejam criados como sendo o diferencial do grupo que é "um só coração". Nesse sentido, o Yudji surge como um grande líder, não apenas por treinar o Samurai ${ }^{4}$, mas por conta da capacidade de promover discursos com forte carga emotiva, que comovem a todos e inspiram os tocadores. Além da questão da organização dos tocadores, há também a liderança e organização das mães e pais. O coordenador do Ishindaiko é chamado de tio Nelson por todos, e cuida de questões financeiras entre outras responsabilidades administrativas.

\section{UM PROCESSO RITUAL - COMPOSTO DE PERCEPTOS E AFETOS.}

Nas vésperas do campeonato presenciei um treino diferenciado, ministrado pelo Lucas Muraguchi, que, a meu ver, possui resquícios de um ritual. Para esclarecer o que entendo por ritual, devo mencionar o antropólogo Victor Turner, que pensa o ritual enquanto momento povoado de simbologias e representações, que promovem uma alteração no estado do ser. Resumindo, e muito, a analise desse autor sobre o tema, pontuo aqui apenas o básico para entender o ritual enquanto performance, enquanto momento em potência. Para além do conceito de ritual, gostaria também de abordar brevemente os ritos de passagem, por esse treino ter sido descrito enquanto tal por Muraguchi e por ter observado algumas relações.

por jovens que nunca haviam participado de nenhum campeonato e eram relativamente novos no Ishindaiko.

${ }^{4}$ Nome interno de um dos grupos do Livre, que apresentou no campeonato uma musica com base na mitologia dos Samurais. A musica se chama "Ken ni iki, ken ni taore", que significa "Viver pela espada, morrer pela espada". 


\section{SEMINÁRIO DE PESQUISA EM CIÊNCIAS HUMANAS - SEPECH \\ Humanidades, Estado e desafios didático-científicos \\ Londrina, 27 a 29 de julho de 2016}

Vale ressaltar que essa leitura superficial do Turner tem o intuito de abordar apenas aquilo que me interessa para pensar a realidade observada, sem a premissa de dissecar a analise do autor. Através do conceito de liminaridade, desenvolvido em "Betwixt and Between", o ritual de passagem é pensado por Turner enquanto um período em que a estrutura está suspensa por alguns instantes, ao mesmo tempo em que é reforçada. Há diversas problemáticas teóricas que me impedem de usar o Turner plenamente para pensar o treino das 100 vezes, entretanto, insisto em apresentar alguns elementos que me remeteram a leitura de tal autor. O treino das 100 vezes enquanto preparação final para o campeonato me pareceu surpreendente devido não apenas a capacidade de criação na forma de tocar, mas também na capacidade de provocar estados diferenciados de percepção.

Performar a mesma música, repetidamente, de maneiras inusitadas, onde cada performance sela um desafio, suspende a estrutura "normal" da música, habitual e constantemente treinada. Apesar de desafios desse tipo terem ocorrido antes, um treino dedicado a eles, com a meta das 100 vezes, é uma experiência a parte, apesar dos fatores extraordinários irem além da forma de tocar a música e os resquícios do ritual se tornarem mais notáveis ao final do dia. Mas ainda sobre as 100 vezes, pude observar que ao mesmo tempo que a estrutura da música é suspensa em alguns elementos, é reforçada a partir do momento que os tocadores precisam apresentar um domínio para além do que estão acostumados a fazer, sendo treinados a lidar com o imprevisível.

Outro fator importante desse treino é a questão física. Os tocadores são conduzidos a uma exaustão descomunal, sem momentos para pausa, seguem executando a mesma musica de formas diversas durante horas a fio. Esse aspecto me chamou atenção pensando na descrição de ritos, principalmente de passagem, por Pierre Clastres em "A tortura na sociedade primitiva". Segundo Clastres, constantemente os rituais submetem o corpo do iniciado a torturas. Essas torturas se inscrevem no corpo, e, se as técnicas variam de sociedade para sociedade, o objetivo permanece o mesmo: o iniciado precisa sofrer. É obvio que o sofrimento imposto aos tocadores do Ishindaiko pode ser considerado leve em comparação aos descritos por Clastres em outros rituais, entretanto, viso aqui traçar elementos que apontam resquícios de um ritual na pratica do grupo, afinal, esse treino sequer é reconhecido conscientemente por eles como detentor de alguma função ritualística.

A forma como o treino das 100 vezes conduz o corpo dos tocadores a extremos, e mais do que isso, como a cada momento que passam nessa condição eles apresentam ainda mais força para tocar, como se a vitalidade aumentasse à medida que a exaustão se instaurava no corpo é um dado que me remete a questão da resistência dos iniciados nos rituais, fator importante na literatura clássica a respeito e presente em Clastres, apesar de que para ele, esse fator sozinho não explicar toda a complexidade do sofrimento imposto nos rituais e o ensinamento do coletivo ao iniciado. A memória inscrita no corpo, através de cicatrizes, não está presente no treino especial, entretanto, o corpo é marcado de outras formas e a memória coletiva é ativada logo em seguida. Após as cinco vezes sem parar finais, os tocadores terminam as 100 vezes em um relaxamento no escuro, conduzido por falas de duas figuras referenciais no Ishindaiko: Lucas Muraguchi e Yudji Higashi.

A história contada pelo Lucas projetava o futuro como presente e conduzia os integrantes ao campeonato, narrando o que aconteceu. $\mathrm{Na}$ fala, os tocadores do Junior passavam por todos os preparativos para entrada no palco: os pensamentos, a 


\section{SEMINÁRIO DE PESQUISA EM CIÊNCIAS HUMANAS - SEPECH \\ Humanidades, Estado e desafios didático-científicos \\ Londrina, 27 a 29 de julho de 2016}

ansiedade, a concentração. A performance foi narrada como atingindo os tempos ideais de 1 minuto para a primeira música e 4 min e 45 segundos a apresentação total. A condução da história era rica em detalhes e emoção: a saída do palco, os familiares e apoios que sustentam os jovens tocadores, tudo entrelaçado na trama do campeonato que passou após aqueles breves minutos e se resumia agora no sentimento de dever comprido e comemoração com os entes queridos. A sala estava escura, mas uma luz entrava sutilmente através do lado de fora, criando uma atmosfera teatral, onde o fundador do Ishindaiko era levemente iluminado enquanto contava um sonho em frente ao Odaiko, que compunha a cena.

Após o Lucas, o Yudji assumiu a fala por convite da Cintia, para que conversasse com os jovens tocadores. Logo no inicio a voz que contava a história do passado, dos Junior que ganharam o campeonato brasileiro de taiko e como foi sua trajetória, indicava as lágrimas que a memória provocava. A emoção foi crescendo em cada palavra e o conto do campeonato passado fez com que as lagrimas se proliferassem por todo o espaço. Assistindo a cena, estavam juntamente comigo os tocadores do Livre, Samurai, que acompanhavam em silencio tudo que ocorria. Ao terminar, Yudji levantou os tocadores organizando uma roda, abraçados, com um gesto chamou todos que estavam no local para se aproximarem. Todos colocaram as mãos nas costas dos Junior que estavam no centro, e a fala do Yudji ressaltava o apoio, a união, a força, e acima de tudo: o quanto eles não estavam sozinhos e o que representavam.

O Banzai (saudação que deseja vida longa e antigamente era usado como grito de guerra) que é usado antes das apresentações foi feito de forma intensa. Esse grito possui uma definição ambígua, pois ao mesmo tempo em que remete a alegria e saudação de longevidade, e pode ser usado em festas, também é um grito de desespero usado em momentos de guerra e morte eminente. Mergulhados em lagrimas, exaustos, emocionalmente frágeis devido à pressão do campeonato, o grito tomou proporções catárticas, misturando tanto desespero quanto alegria. Após esse momento, os tocadores do Junior foram conduzidos no escuro para seus instrumentos, para performar a ultima vez na noite, as músicas do campeonato.

Começaram tocando no escuro, os integrantes do Livre permeavam o ambiente soltando os kiais, termo que se refere à exteriorização da energia corporal, juntamente com o Junior. Durante os solos, os gritos se concentravam nos tocadores que estavam tocando, movendo-se rápido pelo espaço e ecoando kiais por toda a música. As luzes acenderam nesse momento e todos acompanhavam aquela performance impecável. Quando terminou, pude anunciar que os tempos ideais de: 1 min primeira música e 4 e 45 segundos da segunda, que não haviam sido alcançados antes no treino, foram concretizados. Todos os presentes estavam comovidos com tudo que ocorreu, e penso ter sido um momento de catarse para os tocadores do Junior e fortalecimento dos laços sociais do coletivo.

Diante disso, penso como a descrição do campeonato no futuro e no passado demonstra alguns aspectos do momento limiar vivido pelos tocadores, pois viviam o quase-campeonato, a véspera onde $\mathrm{o}$ psicológico sofre com as pressões $\mathrm{e}$ responsabilidades de forma mais intensa, momento em que não havia mais tempo de treino mas ainda não haviam realizado sua responsabilidade. Vejo como o treino teve elementos de rituais por conta da alta dramaticidade, performance, intensificação do pertencimento ao coletivo, jogo com as estruturas, e principalmente, por conta da efetividade que teve nos Juniors, que foram os atores centrais de toda a trama, expresso 


\section{SEMINÁRIO DE PESQUISA EM CIÊNCIAS HUMANAS - SEPECH \\ Humanidades, Estado e desafios didático-científicos \\ Londrina, 27 a 29 de julho de 2016}

pelos tempos alcançados nas musicas ao final de tudo. A questão do psicológico e do apoio é tratada com seriedade pelos membros do Ishindaiko, que além desse treino especial, promoveram um amigo secreto de cartas para incentivar e dar forças uns aos outros.

\section{TRIBALISMO ESCANCARADO}

Ao me deparar com a obra "O tempo das tribos" de Maffesoli, encontrei conceitos chaves para pensar o Ishindaiko. Para o autor, observamos na sociedade pós-moderna um retorno de elementos "arcaicos", de valores comunitários e tendências à constituição de clãs urbanos, onde o aspecto cultural se sobressai sobre o econômico e o politico. Esse movimento é marcado por traços como a valorização dos saberes interstícios em contraposição aos saberes "dominantes". O tribalismo emerge como um retorno dos traços dionisíacos, após um momento de excesso de valores apolíneos, sendo esse um movimento em espiral para Maffesoli. Isso implica que atualmente, após um período marcado pela racionalidade instrumental e domínio do logos, acompanhamos a emergência do eros, através da valorização dos sentimentos, dos afetos, do gozo e do corpo.

A juventude constitui, em Maffesoli, os protagonistas principais desse retorno ao dionisíaco da existência. É importante pontuar que para ele, o tribalismo pode estar mascarado em muitos espaços, como por exemplo, um grupo de estudos acadêmicos. Entretanto, busco aqui demonstrar o tribalismo escancarado que se apresenta através do grupo Ishindaiko, para pensar esse fenômeno da sociedade pós-moderna enquanto um possível "reencantamento do mundo" por parte da juventude, através de transformações no âmbito dos relacionamentos e da cultura. O Ishindaiko apresenta em suas práticas elementos do retorno do eros e o respeito dos valores comunitários, onde o grupo se porta como o centro e prevalece sobre posições individuais, criando o sentimento de pertencimento entre seus membros.

Uma das chaves centrais para compreender o retorno do Eros em Maffesoli é a sacralização das relações sociais. No tribalismo, as emoções e paixões coletivas são potencializadas e o quotidiano é permeado por rituais. Há, portanto, uma valorização das experiências oníricas compartilhadas pelo grupo, das fantasias coletivas e manifestações lúdicas. A dimensão "afetual" está na base da estrutura das relações dentro do coletivo. Durante minha vivência com o Ishindaiko pude observar o grupo manifesta instantes de êxtase ao tocar coletivamente. A própria definição do que é Taiko para o Ishindaiko em seu site online demonstra esse aspecto, pois para eles, essa "É uma arte normalmente coletiva que exige a comunhão espiritual daqueles que a buscam." Em maior ou menor escala dependendo das circunstancias externas, o Ishindaiko intensifica os momentos sagrados do cotidiano; como por exemplo, nas vésperas do campeonato, as práticas que visam unificar o grupo e afirmar o pertencimento e os elementos espirituais e afetivos que os unem, é mais corriqueiro do que após o campeonato, nos meses do começo do ano.

Esses aspectos de euforia, prazer, sentimento de pertencimento e diluição do eu dentro de um todo que é maior, são os pontos centrais para se pensar a transformação das relações pessoais que estão ocorrendo nos cenários urbanos, principalmente entre os jovens, que buscam um retorno a tradições que mantiveram os valores "arcaicos" de um 


\section{SEMINÁRIO DE PESQUISA EM CIÊNCIAS HUMANAS - SEPECH \\ Humanidades, Estado e desafios didático-científicos \\ Londrina, 27 a 29 de julho de 2016}

momento pré-individual. As tensões e jogos que são estabelecidos entre a tradição e a juventude, os elementos contraditórios que se entrelaçam e fundem no tribalismo, são aspectos claramente presentes no grupo Ishindaiko.

A inovação do Ishindaiko, uma de suas marcas principais, esbarra em certos limites que a tradição impõe, através do campeonato. Em um dos anos da competição, o grupo decidiu que iria de fato inovar, quebrando comportamentos fundamentais para a cultura japonesa, transgredindo padrões básicos instituídos para a performance do taiko. Apesar de ter sido uma apresentação emocionante, o grupo saiu do campeonato sem nenhuma premiação, fato que nunca havia acontecido anteriormente. Para Muraguchi, o campeonato coloca os pés do grupo no chão, e isso é bom para que eles não se percam em suas criações.

A questão do reconhecimento através da conquista do campeonato é um elemento fundamental para compreender a dinâmica interna do grupo. Em minha analise, o campeonato é o momento em que a tradição "fiscaliza" a prática dos grupos de taiko que se espalham pelo país, onde as gerações são colocadas em confronto, e os jovens precisam demonstrar de forma equilibrada, o respeito aos antigos e a sua forma de realizar a arte milenar, ao mesmo tempo em que apresentam a vitalidade inovadora que lhes é esperada.

\section{CONCLUSÃO}

A tendência apresentada por Maffesoli da pós-modernidade caminhar para uma transformação das relações individuais entre grupos contratuais para pessoas com tribos afetuais parece ter sido efetivada dentro do grupo percussivo Ishindaiko. A arte do taiko é pautada na tradição oral e as informações são transmitidas de forma "orgânica", na convivência com senseis. Não há um modelo rígido nem um código de regras a seguir; a memória é um aspecto importante para os tocadores, pois não há partituras, e é a partir da inscrição no corpo de cada toque, através da repetição, que se internalizam as músicas. $\mathrm{O}$ corpo enquanto um elemento central e valorizado é um dos aspectos do eros dionisíaco do tribalismo.

Maffesoli apresenta argumentos de uma dissolução dessa identidade individual devido ao coletivo. Creio que ao analisar o grupo, da para perceber que em relação aos demais "clãs", a identificação com o grupo atinge níveis pessoais, de identidade do $e u$, enquanto que dentro das práticas cotidianas no interior do grupo, o sentimento de pertencimento dilui o individuo e integra a pessoa em uma construção de self coletivo, próximo da descrição de Maffesoli. O elemento de solidariedade que esses grupos geram dentro de um cenário urbano caótico é central para compreender o fenômeno de "reencantamento do mundo", e o retorno da empatia que podemos observar emerge como uma aparente necessidade diante de uma sociedade que viu os planos da razão instrumental e do progresso fracassar.

Busquei nesse artigo apresentar brevemente conceitos centrais de Maffesoli em "O tempo das tribos" através de um exemplo empírico que permeia o cenário cultural juvenil da cidade de Londrina. Devido ao limite de paginas, não cabia detalhar aspectos técnicos do taiko e as influencias que permeiam o grupo em sua forma de tocar, ou até mesmo, detalhar os subgrupos do Ishindaiko que são criados devido ao campeonato. Entretanto, sua concepção de si enquanto família e os aspectos rituais, 


\section{SEMINÁRIO DE PESQUISA EM CIÊNCIAS HUMANAS - SEPECH \\ Humanidades, Estado e desafios didático-científicos \\ Londrina, 27 a 29 de julho de 2016}

como o treino das 100 vezes, são alguns traços que me tocaram durante a vivência em campo e instigam a suscitar esses diálogos com os autores apresentados.

\section{REFERÊNCIAS}

CLASTRES, Pierre. "Da tortura nas sociedades primitivas" In: A sociedade contra o Estado. São Paulo: Cosac \& Naify, 2003 [1974]

MAFFESOLI, Michel. "O tempo das tribos: o declínio do individualismo nas sociedades de massa” Rio de Janeiro, Editora Florense Universitária, 2006.

TURNER, Victor. "Betwixt and Between: O período limiar dos ritos de passagem" In: Florestas de Símbolos. Niterói, Eduff, 2005. 